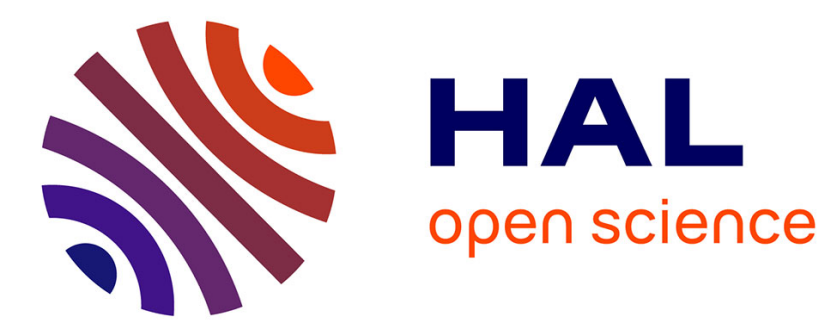

\title{
Photo-physical effects of the chemical insertion of the dimethyl-amine moiety on the newly synthesized oligophenylene (OMPA)
}

M. Chemek, S. Ben Amor, W. Taouali, E. Faulques, M. Bourass, D. Khlaifia, A. Haj said, K. Alimi

\section{To cite this version:}

M. Chemek, S. Ben Amor, W. Taouali, E. Faulques, M. Bourass, et al.. Photo-physical effects of the chemical insertion of the dimethyl-amine moiety on the newly synthesized oligophenylene (OMPA). Journal of Molecular Structure, 2021, 1241, pp.130599. 10.1016/j.molstruc.2021.130599 . hal-03287971

\section{HAL Id: hal-03287971 \\ https://hal.science/hal-03287971}

Submitted on 21 Jul 2021

HAL is a multi-disciplinary open access archive for the deposit and dissemination of scientific research documents, whether they are published or not. The documents may come from teaching and research institutions in France or abroad, or from public or private research centers.
L'archive ouverte pluridisciplinaire HAL, est destinée au dépôt et à la diffusion de documents scientifiques de niveau recherche, publiés ou non, émanant des établissements d'enseignement et de recherche français ou étrangers, des laboratoires publics ou privés. 


\title{
Photo-physical effects of the chemical insertion of the dimethyl-amine moiety on the
} newly synthesized oligophenylene (OMPA)

\author{
M.Chemek $^{\text {a }}$, S.BenAmor ${ }^{\text {, }}$,W. Taouali ${ }^{\mathrm{a}}$ E.Faulques $^{\mathrm{c}}$, M.Bourass ${ }^{\mathrm{d}}$, D. Khlaifia ${ }^{\mathrm{a}, \mathrm{g}}$, A. Hadj \\ said $^{\text {e,f }}$, and K. Alimi ${ }^{\mathrm{a}}$
}

${ }^{a}$ Laboratoire de recherche: Synthèse asymétrique et ingénierie moléculaire de matériaux organiques pour l'électronique organique (LR18ES19), Faculté des Sciences de Monastir, 5000 Monastir, Tunisie.

${ }^{b}$ Department of Chemistry, Faculty of Sciences of Gafsa, university of Gafsa, 2100 Gafsa, Tunisia

${ }^{c}$ Institut des Matériaux Jean Rouxel, CNRS-UMR 6502, 2 Rue de la Houssinière, BP 32229, 44322 Nantes cedex

3, France.

${ }^{d}$ Université de Bordeaux, Institut des Sciences Moléculaires, ISM UMR 5255 CNRS, 351 Cours de la Libération, Talence Cédex, F-33405, France

${ }^{e}$ Laboratoire Interfaces et Matériaux Avancés, Faculté des Sciences de Monastir. Université de Monastir. 5000 Monastir, Tunisie

${ }^{\mathrm{f}}$ Centre de Recherche en Microélectronique et Nanotechnologie de Sousse, Novation City, 4000, Sousse, Tunisie

${ }^{g}$ Physics Department, Faculty of Arts and Science, Jouf University, Qurayyat 77451, Kingdom of Saudi Arabia

*Corresponding author: E-mail: kamel.alimi@fsm.rnu.tn

Faculté des Sciences de Monastir 5000 Monastir. Tunisia.

Tel: 216.73.500.274, Fax: 216.73.500.278

\section{Abstract}

The synthesized oligo[4-(methoxyphenyl) acetonitrile] (OMPA) was chemically modified by Knoevenagel condensation of OMPA with dimethylformamide dimethyl acetal (DMF-DMA).

The obtained oligomer is composed of short chains of poly [3-(dimethylamino)-2-(4methoxyphenyl)acrylonitrile] and denoted OMFA. Experimental measurements: ultravioletvisible (UV-vis), steady-state and time-resolved photoluminescence spectroscopies, infrared spectroscopy, and thermogravimetric analysis(TGA), were combined with theoretical calculation, based on DFT methodologies, to highlight the effect of the grafting of the dimethyl-amine group on the photo-physical and electronic properties of the as-synthesized oligomer. Thus, a redshift of the absorption and photoluminescence spectra is observed upon the chemical grafting of the functional group. Added to that, a decrease of the optical bandgap $\left(E_{g}^{o p t}\right)$ and the energy gap $\mathrm{E}_{\mathrm{H}-\mathrm{L}}=\mathrm{E}_{\mathrm{HOMO}}-\mathrm{E}_{\mathrm{LUMO}}$ occurs upon the chemical modification. Density functional theory (DFT) computations show that the chemical insertion of the dimethyl-amine group into the monomer and the oligomer induces a drastic change on their frontier orbitals HOMO and LUMO. 
Keywords: 4-(methoxyphenyl)acetonitrile, Dimethylformamide Dimethyl Acetal (DMFDMA), Optical properties

\section{I-Introduction}

Since the discovery of the light-emitting properties in thephenylene-based conjugated polymers in 1990 [1], potential device applications have been developed, going from optical switching to solar cells [2]. Furthermore, progress in the studying of the fundamental physics of these conjugated polymers provides crucial underpinnings to technological research. These signs of progress have been developed experimentally and using newly computational tools [3-5]. In this frame, the comprehension of the correlation between structure and photo-physical properties will provide useful information to design new materials with desired properties and functionalities. Indeed, the photo-physical properties of organic-based materials could be tuned by modulating their electronic structures [6-8]. This purpose could be achieved by incorporating appropriate electron-donating or electron-withdrawing groups in the structure of the starting monomer or of the final polymer. Unfortunately, the choice of monomers with appropriate groups is limited since not all of these groups are necessarily tolerant of the synthetic pathway of the polymer. Thus, the post-synthetic covalent modification of the polymeric backbone, by grafting different molecular moieties, is a more versatile strategy that offers more possibilities for controlling the chemical structure of the final material. However, this strategy is not always successful with long polymeric chains because of the steric hindrance effect, solubility problems, and applicability limitation due in particular to low PL quantum yield efficiencies in the condensed state [9]. A way to circumvent these problems is to design small molecules or oligomers that could be used as active layers in organic solar cells, light-emitting diodes, or other sensors [10-12]. Previously, we have synthesized new

oligophenylene derivatives by electro-oxidative oligomerization of the 4(methoxyphenylacetonitrile) monomer (referred to as MPA) [13]. The obtained oligomer, 
oligo[4-(methoxyphenyl)acetonitrile $]_{\mathrm{n}}$, (OMPA), was also successfully characterized by various experimental techniques [13]. Besides, DFT calculations were undertaken to describe the possible mechanism of the electro-oxidative oligomerization. The theoretical and experimental analysis showed that the average length chain is at about 5 units (5-MPA) [13, $14]$.

In this paper, we have modified the chemical backbone of the OMPA synthesized oligomer by the Knoevenagel condensation with the dimethylformamide dimethyl acetal (DMF-DMA). Photo-physical properties of the new oligo [3-(dimethylamino)-2-(4methoxyphenyl)acrylonitrile] (OMFA) were studied by the means of optical absorption, steady-state, and time-resolved photoluminescence techniques and compared to those of the unmodified OMPA. We present the chemical modification route and the effect of the grafting of the dimethyl-amino group on the photo-physical properties of the synthesized OMPA as well as DFT calculations to better understand the photophysical and electronic properties of this compound.

\section{II-Experimental and theoretical details}

4-Methoxyphenyl acetonitrile,N,N-Dimethylformamide dimethyl acetal, and tetraethylammoniumtetrafluoroborate were purchased from ACROS. Chloroform and dichloromethane were purchased from PROLABO. Diethyl ether, ethanol, petroleum ether, and acetonitrile were purchased from PANREAC.

Optical absorption measurements were carried out at room temperature (RT) using a Varian Cary 5G spectrophotometer. Continuous-wave photoluminescence measurements (PL) were collected on a Jobin-YvonFluorolog 3 spectrometer using a Xenon lamp (450W).

Time-resolved photoluminescence experiments (TRPL) were carried out at room temperature with a regeneratively amplified femtosecond Ti:Sapphire laser system (SpectraPhysics Hurricane X) generating $100 \mathrm{fs}$ pulses at $800 \mathrm{~nm}$ with a repetitive rate of $1 \mathrm{kHz}$ and 
an average power of $1 \mathrm{~W}$. The laser line is frequency-tripled to obtain an excitation line $\chi_{\mathrm{exc}}=$ $266 \mathrm{~nm}$. Optical measurements of the samples (OMPA and OMFA) were investigated in dilute chloroform solution and as thin films. For optical measurements, a diluted chloroform solution of OMPA and OMFA $\left(\mathrm{C}=1.5 \times 10^{-5} \mathrm{M}\right)$ was prepared. Thin films were obtained by simple deposition of a prepared chloroform solution $\left(\mathrm{C}=1.5 \times 10^{-3} \mathrm{M}\right)$ by drop-coasting onto silica.

The voltammetric study was performed with a Voltalab10 apparatus from a Radiometer driven by the Volta Master software. The working electrode was a $2 \mathrm{~mm}$ diameter platinum disk, the reference electrode was an SCE (Tacussel SR110) and the counter electrode was a platinum wire. The preparative electrolyzes were carried out in a two-compartment cell, under nitrogen, at a controlled potential versus an SCE (Tacussel C12). The potentiostat and the current integrator were Tacussel (PRT 1-100 and IG 5 respectively). The working electrode and the counter electrode were a $4 \mathrm{~cm}^{2}$ and a $0.25 \mathrm{~cm}^{2}$ platinum gauze, respectively. The separation between cell compartments was realized by a number 4 glass frit.

Quantum chemical computations were performed using DFT [15] implemented in Gaussian 16 program [16]. All calculations on the studied molecules of this work were done at the Performance Computing Center Bordeaux University. Molecular geometries were optimized in theground statewith the Becke-3-Lee-Yang-Parr (B3LYP) exchange-correlation functional[17], LSDA(SVWN5) [14], and PBE0 functional combined with the 6-311G (d,p) basis set[18].LSDA(SVWN5) was used in modelling the unmodified oligomer (OMPA), and it overestimates its experimental vibrational, electronic and optical properties.[14]. PBE0 functional was successfully tested for several small molecules [19-20]. The calculated absorption spectrum of the investigated oligomer was obtained by the Time-Dependent Density Functional Theory (TD-DFT) method. The NBO calculations were performed using NBO 3.1 program as implemented in the Gaussian 16 package. The molecular electrostatic 
potential mapping (MEP) and the contour plots of the different orbitals were also visualized and obtained from the fully optimized state on the ground state using the GAUSSVIEW program [21].

\section{III-Chemical synthesis procedure:}

The unmodified oligomer OMPA was electrochemically prepared by the electrolysis of (4-methoxyphenyl) acetonitrile at a controlled potential of $1.8 \mathrm{~V}$ as described in our previous work [13]. In this part, we will firstly describe the modification of the chemical structure of the 4-Methoxyphenylacetonitrile (MPA) monomers by Knoevenagel condensation of MPA with dimethylformamide dimethylacetal (DMF-DMA), and secondly explain the synthesis of OMFA oligomer.

$1 \mathrm{mmol}$ of the monomer was dispersed in $25 \mathrm{ml}$ of anhydrous toluene under stirring. After that, $1 \mathrm{mmol}$ of dimethylformamide dimethylacetal was added to the dispersion. The mixture was refluxed and stirred under an argon atmosphere for 24 hours. The reaction was monitored by TLC. The modified monomer, (Z)-3-(dimethylamino)-2-(4methoxyphenyl)acrylonitrile (MFA), was collected by chromatographic separation on a silica gel column using a mobile composed of phase $20 \%$ ethyl acetate and $80 \%$ cyclohexane. The obtained MFA exhibits good solubility in commonly used organic solvents such as chloroform $\left(\mathrm{CHCl}_{3}\right)$, dichloromethane $\left(\mathrm{CH}_{2} \mathrm{Cl}_{2}\right)$, and THF. The chemical structure of the modified and unmodified monomers (MPA/MFA) was checked first by ${ }^{1} \mathrm{H}$ and ${ }^{13} \mathrm{C}$ NMR spectroscopies in $\mathrm{CDCl}_{3}$. For the ${ }^{1} \mathrm{H}$ NMR spectrum of MPA, the signal at $3.8 \mathrm{ppm}$ was assigned to the benzylic and the methylic protons. The aromatic protons appear between 6.6 and $7.5 \mathrm{ppm}$ [13]. The spectrum of MFA exhibited a singlet at $\delta=3.19 \mathrm{ppm}(6 \mathrm{H})$, a singlet at $\delta=3.79 \mathrm{ppm}(3 \mathrm{H})$, a singlet at $\delta=6.76 \mathrm{ppm}(1 \mathrm{H})$, and two doublets at $\delta=6.84 \mathrm{ppm}(2 \mathrm{H}, \mathrm{J}=8,7$ $\mathrm{Hz})$ and $\delta=7.25 \mathrm{ppm}(2 \mathrm{H}, \mathrm{J}=8,7 \mathrm{~Hz})$. These signals are assigned to methylamine protons, methoxyl protons, the methylene proton, and the aromatic protons, respectively. This result 
confirmed the structure of the MFA and indicatedthe successful chemical modification of MPA. Scheme 2 presents the chemical synthesis process of the MPA monomer.

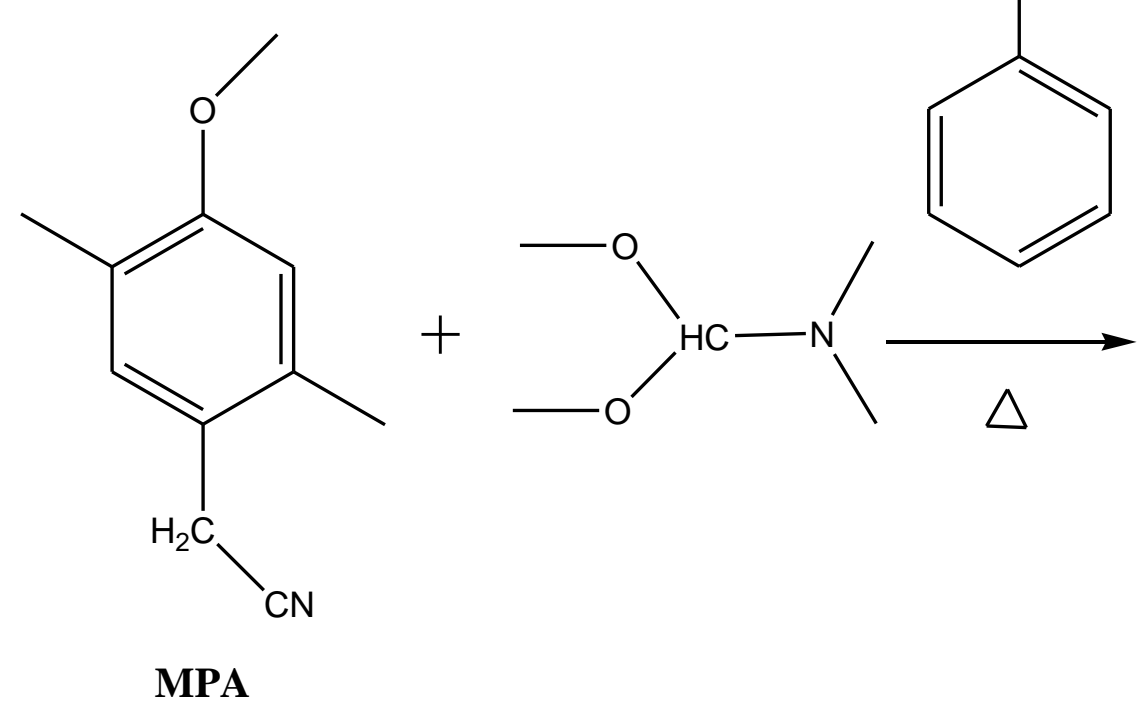

MPA

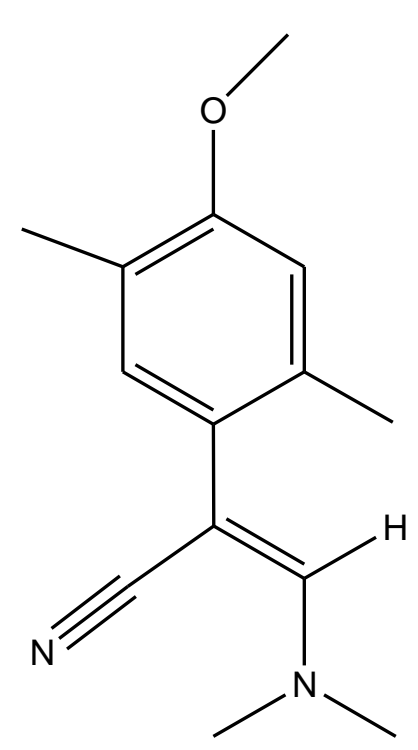

MFA

Scheme 2: MFA chemical synthesis process

The ${ }^{13} \mathrm{C}$ NMR spectrum of MFA, presents main chemical signals at: $\delta=42,51,55.43$, $76.48,114.22,121.49,125.54,129.19,149.25$ and $157.62 \mathrm{ppm}$ assigned to carbons $\mathrm{C}_{26} / \mathrm{C}_{22}$, $\mathrm{C}_{10}, \mathrm{C}_{12}, \mathrm{C}_{1} / \mathrm{C}_{3}, \mathrm{C}_{7}, \mathrm{C}_{4} / \mathrm{C}_{5}, \mathrm{C}_{6}, \mathrm{C}_{11}$ and $\mathrm{C}_{2}$, respectively (structure depicted in Scheme 1).

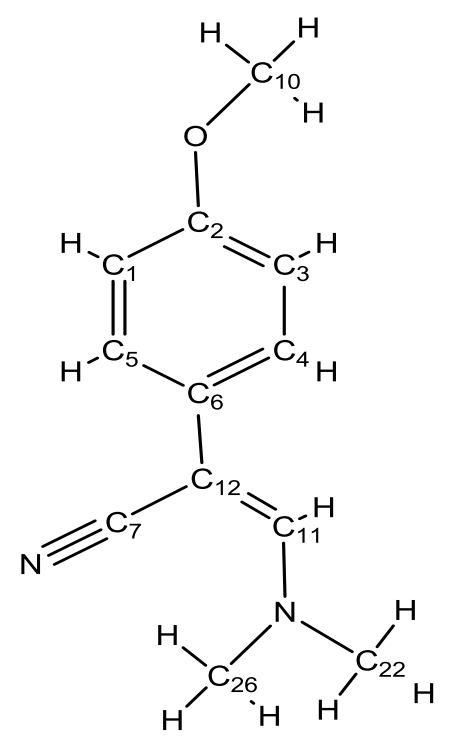

Scheme 1: Chemical structure of the obtained (Z)-3-(diméthylamino)-2-(4-méthoxyphenyl) acrylonitrile (MFA) 
The same previously described experimental procedure was used for the oligomer OMPA modification. The modified oligomer was filtered after precipitation in diethyl ether. The yieldobtained was about $60 \%$. The oligomer obtained exhibits good solubility in commonly used organic solvents such as chloroform $\left(\mathrm{CHCl}_{3}\right)$, dichloromethane $\left(\mathrm{CH}_{2} \mathrm{Cl}_{2}\right)$, and THF. Scheme 3 presents the chemical condensation of OMPA

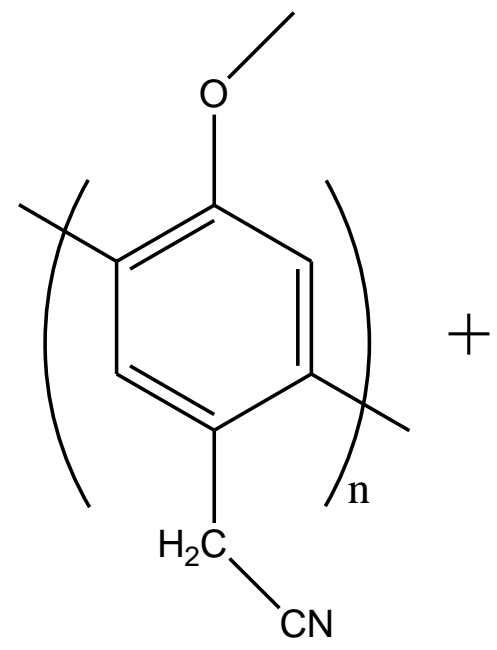

OMPA

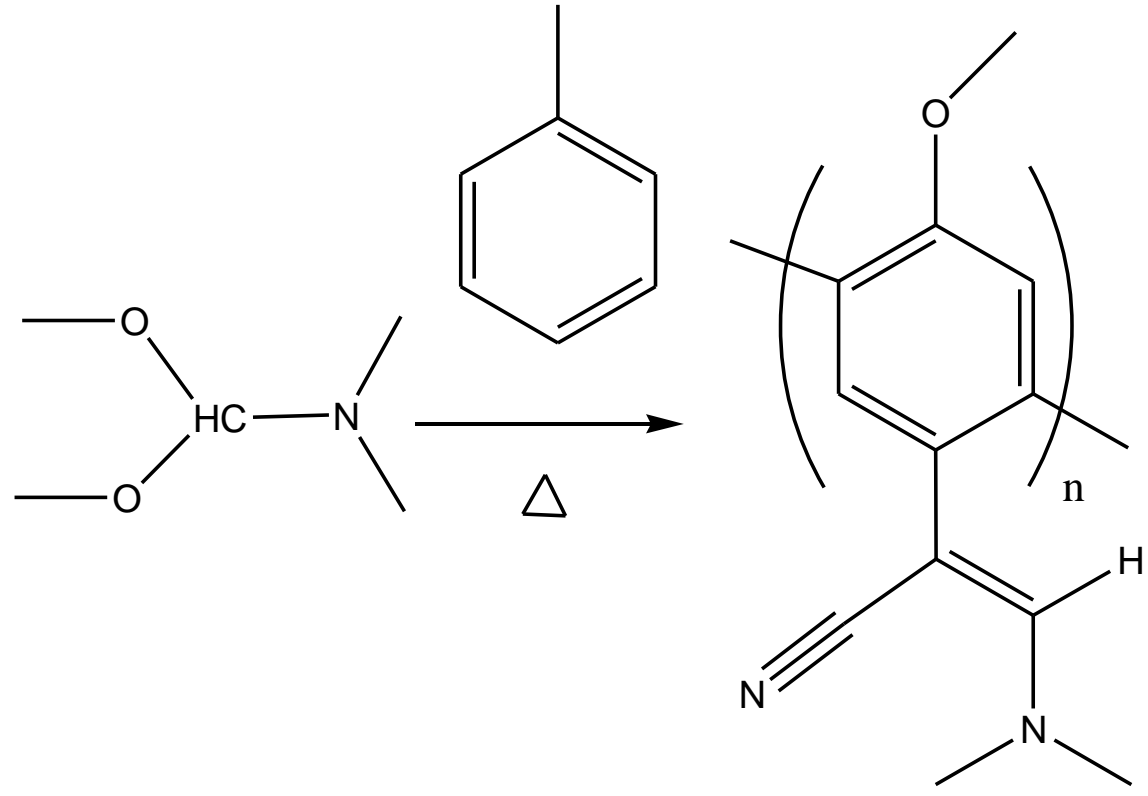

OMFA

Scheme 3: Chemical synthesis of OMFA oligomer

The analysis of the ${ }^{1} \mathrm{H}$ and ${ }^{13} \mathrm{C}$ NMR spectra of the modified oligomer confirmed that the Knoevenagel condensation of the oligo (4-Methoxyphenylacetonitrile) (OMPA) with dimethylformamide dimethyl acetaloccurred with a quantitative yield.The recorded signals,for both spectra, appeared at almost the same chemical shifts as for the modified monomer. Particularly, in the ${ }^{13} \mathrm{C}$ NMR spectra, we note the appearance of the signal at $42 \mathrm{ppm}$, corresponding to the methyl carbons of the dimethyl-amine group. Added to that, the signal at $23 \mathrm{ppm}$, corresponding to benzylic carbons observed in the ${ }^{13} \mathrm{C}$ NMR spectrum of OMPA with high intensity [13], appears in the ${ }^{13} \mathrm{C}$ NMR spectrum of OMFA with weak intensity, and 
evidenced the quantitative or partial modification. The obtained material Oligo((Z)-3(diméthylamino)-2-(4-méthoxyphenyl) acrylonitrile) denoted (OMFA)

\section{IV-Experimental investigations}

\section{IV-1-Electrochemical measurements}

Cyclic voltammetry measurements were performed using a three-electrode cell setup with $0.1 \mathrm{M}$ tetrabutylammoniumtetrafluoroborate $(\mathrm{Bu} 4 \mathrm{NBF} 4)$ as a supporting electrolyte in degassed acetonitrile. We studied the electrochemical behavior of the oligomers to understand their electrochemical stability in $\mathrm{p}$ and $\mathrm{n}$-doped states. Figure 1 illustrates the cyclic voltammograms of the OMFA oligomer. The $\mathrm{E}_{\mathrm{HOMO}}$ and the $\mathrm{E}_{\mathrm{LUMO}}$ were calculated with the empirical method [22-23], where: $\mathrm{E}_{\mathrm{HOMO}}(\mathrm{eV})=-\left(\mathrm{E}_{\text {onset oxi }}+4,4\right)$ and $\mathrm{E}_{\mathrm{LUMO}}(\mathrm{eV})=-\left(\mathrm{E}_{\text {onset red }}\right.$ $+4,4)$ with the onset potentials were measured vs. an ECS electrode. $E_{\text {onsetoxi }}$ and $E_{\text {onset red }}$ were estimated from the obtained cyclic voltammograms $\left(\mathrm{E}_{\text {onsetoxi }}=1.4 \mathrm{eV}, \mathrm{E}_{\text {onset red }}=-0.9 \mathrm{eV}\right)$. Energy gap was also deduced by $\mathrm{E}_{\mathrm{H}-\mathrm{L}}=\mathrm{E}_{\mathrm{HOMO}}-\mathrm{E}_{\mathrm{LUMO}}$ which is estimated to be $2.33 \mathrm{eV}$. The electrochemical obtained data of the prepared oligomers are presented in Table 2.

\section{IV-2-Infrared observation}

Unmodified and modified oligomers (OMPA and OMFA) are characterized by infrared spectroscopy using the Kbr technique. Normalized infrared spectra of both oligomers are presented in Figure 2 for the range $600-2400 \mathrm{~cm}^{-1}$. Noting that the characteristic vibrations of OMPA are presented and assigned in Figure 1 following the results presented in our previous paper [13]. The chemical condensation of the OMPA oligomer induces a partial effect on the infrared vibrational properties (see Figure 2). In fact, under the Knoevenagel condensation, a new peak appears at around $1388 \mathrm{~cm}^{-1}$ assigned to the $\mathrm{C}-\mathrm{H}$ vibration of the $\mathrm{CH}_{3}-\mathrm{N}-\mathrm{CH}_{3}$ introduced group. We notice the disappearance of the peaks located at 1083 and $1670 \mathrm{~cm}^{-1}$ which are observed in the infrared spectrum of the unmodified OMPA oligomer. Meanwhile, a slight shift of the aromatic $\mathrm{C}=\mathrm{C}$ vibration from 1610 to $1620 \mathrm{~cm}^{-1}$ appears. Also, a decrease 
in the intensity of several collected mode vibrations and especially for the $\mathrm{C}-\mathrm{H}$ vibration at $760-815 \mathrm{~cm}^{-1}$ and that for $\mathrm{C} \equiv \mathrm{N}$ vibration at $2200-2250 \mathrm{~cm}^{-1}$ was observed. These observed trends are the results of the partial grafting of the dimethyl acetal group to obtain the OMFA oligomer.

\section{IV-3-Steady-state optical absorption spectroscopy}

The normalized optical absorption spectrum of OMFA oligomer in solution is depicted in Figure 3A. As mentioned previously [13], unmodified OMPA absorbs in the UV region with optical absorption bands located at 240, 270, and $340 \mathrm{~nm}$ (Figure 3C). From the obtained optical absorption spectrum, the onset of absorption wavelength $\lambda_{\text {onset }}$ is at about $405 \mathrm{~nm}$. Using the following formula $E_{g}^{o p t}=\frac{1242}{\lambda_{\text {onset }}}[24]$, the optical bandgap $E_{g}^{o p t}$ is estimated to be $3.06 \mathrm{eV}$. From the optical absorption spectra of the OMFA oligomer, we deduce that going from OMPA to OMFA no change of the short optical transitions is detected at $240 \mathrm{~nm}$. While the chemical modification induces firstly a redshift of the optical absorption band located at $270 \mathrm{~nm}$ to $290 \mathrm{~nm}$, secondly the $\pi-\pi^{*}$ optical transition shifts from $340 \mathrm{~nm}$ to $380 \mathrm{~nm}$ for the OMFA. Added to that, a red-shift of $\lambda_{\text {onset }}$ is observed from $405 \mathrm{~nm}$ for unmodified OMPA to $457 \mathrm{~nm}$ for OMFA, indicating a decrease in the optical bandgap from 3.06 to $2.71 \mathrm{eV}$ for the OMFA oligomer. To give information on the eventual solid-state effects on the optical properties, the optical absorption spectrum of the OMFA oligomer thin film is presented in Figure 3B. The thin film was obtained by drop-casting a prepared solution of OMFA on a silica substrate. Going from solution to solid-state, a redshift of the detected optical transition was observed, especially the maximum absorption from $380 \mathrm{~nm}$ in solution to $398 \mathrm{~nm}$ in a solid-state. Elsewhere, the onset of absorption increase from $450 \mathrm{~nm}$ to $490 \mathrm{~nm}$ inducing a decrease of the optical bandgap from $2.71 \mathrm{eV}$ to $2.53 \mathrm{eV}$ in a solid-state.

\section{IV-4-Steady-state photoluminescence spectroscopy}


The photoluminescence excitation spectrum (PLE) recorded for the maximum emission $(480 \mathrm{~nm})$ of the OMFA oligomer in chloroform solution was obtained by varying the excitation wavelength from 250 to $450 \mathrm{~nm}$ (Figure 3A). The PLE spectrum presents a maximum optical band at $380 \mathrm{~nm}$, reproducing also the $\pi-\pi^{*}$ optical transition observed in the optical absorption spectra of OMFA obtained in solution.

Figure 4 presents the photoluminescence dependence on the wavelength excitation light: PLE maps of OMPA and OMFA oligomers obtained by varying the excitation wavelength in the UV range under $2 \mathrm{~nm}$ steps. By analyzing the obtained PLE maps, a drastic change was observed in the emission properties going from OMPA to OMFA PLE maps. Under shortwavelength excitation $\left(\lambda_{\mathrm{exc}}=260-320 \mathrm{~nm}\right)$, vibronic photoluminescence spectra with maximum emission at around 360 and $480 \mathrm{~nm}$ were obtained in the case of OMPA. For OMFA, a vibronic emission profile was also obtained under UV excitation (260-300 nm) However, oppositely with that of OMPA, a weak transition at around (300-400 nm) and an intense one at around $500 \mathrm{~nm}$ are observed. Moreover, under higher excitation wavelength ( $\lambda_{\text {exc }}$ varying for 320 to $440 \mathrm{~nm}$ ) a broader unstructured emission profile was obtained for both oligomers. Meanwhile, going from OMPA to OMFA a red-shift of the maximum emission was obtained, indicating an enhancement of the effective conjugation lengths [24,25]. Moreover, we present in Figure 5 the photoluminescence spectra of OMPA and OMFA under both short $\left(\lambda_{\text {exc }}=290 \mathrm{~nm}\right)$ and high excitation wavelength $\left(\lambda_{\mathrm{exc}}=360 \mathrm{~nm}\right)$. From these spectra, we confirm the assumption derived from PLE maps of the studied oligomers. In fact, under $360 \mathrm{~nm}$ excitation, PL spectra of OMPA and OMFA present a structure less and broad profile. PL spectra of OMFA present a red-shift at around $60 \mathrm{~nm}$ compared to that of OMPA. Under $\lambda_{\mathrm{exc}}=290 \mathrm{~nm}$ excitation, a vibronic PL profile occurs for both oligomers with two emission transitions at around 360 and $490 \mathrm{~nm}$. A strong decrease of the PL maximum emission located at $350 \mathrm{~nm}$ was obtained when going from OMPA to OMFA. From these observations, we can 
deduce that the grafting of the dimethyl-amino group changes dramatically the optical properties and also modify the photo-generated excitonic species. These trends could result from modification of the effective conjugation length under the chemical grafting.

\section{IV-5-Time-resolved photoluminescence investigation}

In this part, time-resolved photoluminescence (TRPL) spectroscopy has been used to better understand the possible photo-physical mechanism such as inter and intra-exciton formation and migration of the photo-generated species into the prepared oligomers. In Figure 6, we present TRPL decays of OMPA and OMFAobtained under laser excitation wavelength at $\lambda_{\text {exc }}=266 \mathrm{~nm}$. Figures $6 \mathrm{~A}$ and $6 \mathrm{~B}$ depict the normalized TRPL dynamics in the $1 \mathrm{~ns}$ range for both oligomers deposited in thin films by drop-casting the oligomer solution onto silica and in diluted chloroform solution in the range $0-5 \mathrm{~ns}$ on a semi-logarithmic scale, respectively.

The dynamics of the photo-excited states of all samples are fitted by a bi-exponential model [26] assuming that the total population of photogenerated species is $n=A_{1} n_{1}+A_{2} n_{2}$, where $A_{1}$ and $A_{2}$ are proportional to the PL intensity from levels 1 and 2, respectively, the average decay time $\tau_{\text {mean }}$ writes as $\tau_{\text {mean }}=\left[\mathrm{A}_{1}\left(\tau_{1}\right)^{2}+\mathrm{A}_{2}\left(\tau_{2}\right)^{2}\right] /\left[\mathrm{A}_{1}\left(\tau_{1}\right)+\mathrm{A} 2\left(\tau_{2}\right)\right]$. The lifetimes presented in Table 1 show two-decay components: a fast one $\left(\tau_{1}\right)$ attributed to the nonradiative recombination, and a slow component $\left(\tau_{2}\right)$ that can be ascribed to the radiative recombination after the interaction. For oligomers prepared in solution, TRPL decays tend to be monoexponential with slower decay time. TRPL decays of thin films present a faster dynamic with biexponential behaviors. The calculated average lifetime $\tau_{\text {mean }}$ for OMFA in dilute chloroform solution is $2.3 \mathrm{~ns}$ and $0.18 \mathrm{~ns}$ in the thick film, while for OMPA $\tau_{\text {mean }}$, it reaches $2.1 \mathrm{~ns}$ in dilute chloroform solution and $0.15 \mathrm{~ns}$ in the thick film. The dramatic decrease of $\tau_{\text {mean }}$ for both oligomers going from solution to thin films is a signature of the increase of the effective conjugation length [27] in the condensed state due to the alignment of the oligomer chain onto the silica substrate, upon chloroform evaporation. In a diluted 
solution, oligomer chains are well separated favoring the formation of singlet intra-chain excitons under laser excitation. In this state, strong intermolecular interactions are negligible and inter-chain migration of the photo-generated species is precluded [28]. Consequently, a strong PL emission is observed in the solution state associated with a slow decay mechanism. Furthermore, in thick film oligomer chains are aggregated in bundles favoring inter-oligomer interaction, which enhances the formation of non-emissive inter-chain photo-generated species migrating rapidly through the material. Consequently, quenching in the emission could be observed with faster decay dynamics.

\section{IV-6-Thermal investigations}

Thermal properties of the modified and unmodified oligomers were investigated by thermogravimetric analysis (TGA) under nitrogen atmosphere. Figure 7 shows the weight loss versus temperature of OMPA and OMFA. Both oligomers present small weight loss (at around $10 \%$ ) under $247^{\circ} \mathrm{C}$, which is, most probably, due to the departure of residual solvents used in the synthesis part and also unreacted used substance under chemical reactions. Until $\mathrm{T} 1=485{ }^{\circ} \mathrm{C}$ a second stability level for OMPA is observed, the insertion of the dimethyl acetal chemical group induces the decrease of the $\mathrm{T}_{1}$ from $485{ }^{\circ} \mathrm{C}$ to $440{ }^{\circ} \mathrm{C}$ due to the degradation of the dimethyl-amine moiety from the backbone of the oligomer. Finally, fast degradation is observed under $485^{\circ} \mathrm{C}$ for OMPA and $440^{\circ} \mathrm{C}$ for OMFA and until at around $600^{\circ} \mathrm{C}$. It is seen that the use of the partial insertion of the chemical $\mathrm{CH}_{3}-\mathrm{N}-\mathrm{CH}_{3}$ induces a slight decrease in the stability of the oligomer.

\section{IV-7-Theoretical investigations}

In this section, DFT quantum chemical calculations are performed to study the effect of the dimethyl-amino group on the optoelectronic properties of the as-synthesized oligomer and to rationalize the obtained experimental observations. In this part, we are going to study the 
effect of the chemical insertion on simple monomer units (MPA) and the oligomer OMPA. The study on the simple monomer is presented in the supplementary data.

Based on our previous paper [14], the 5-MPA oligomer overestimates the experimental properties of the unmodified OMPA oligomer [14]. On the optimized 5-MPA, we graft a dimethyl-amine chemical group (Figure 8). The chemical structure of modified and unmodified 5-MPA is optimized on the ground state with DFT tools and using various functionals. The results listed in Table 2 indicate that DFT/LSDA/6-311G $(\mathrm{d}, \mathrm{p})$ overestimates the $\mathrm{E}_{\mathrm{HOMO}}, \mathrm{E}_{\mathrm{LUMO}}$, and the energy gap $\mathrm{E}_{\mathrm{H}-\mathrm{L}}=\mathrm{E}_{\mathrm{HOMO}}-\mathrm{E}_{\mathrm{LUMO}}$. Similar observations are found for unmodified OMPA [14]. In Figure 8, we present the optimized chemical structure of OMPA and OMFA using DFT/LSDA/6-311G(d,p). Based on the optimized OMFA chemical structure, the theoretical infrared spectrum is computed by DFT/LSDA/6-311G(d,p). As it is shown in the previous paper [29], the calculated frequencies using the used basis set must be corrected with the scale factor 0.988 . The obtained calculated infrared spectrum is presented with the experimental one in Figure 1. It is seen that the theoretical infrared spectrum reproduces experimental one on the obtained band positions and intensities. Also, the theoretical optical absorption spectrum is computed by TD-DFT/LSDA/6-311G(d,p) on chloroform solution and presented with the experimental one (Figure 3D). The obtained simulated optical absorption spectrum reproduces the experimental one with a slight difference in shape. For most of organic conjugated polymer, the first calculated (TD-DFT) vertical electronic transition corresponds to the HOMO->LUMO transition, which energy commonly considered as the optical energy gap [30]. In our case, using Gauss sum software [31] on the obtained TD-DFT calculation, the vertical electronic transition is found at $498 \mathrm{~nm}$ with a weak oscillator strength $\mathrm{f}(0.012)$, and correspondingto HOMO->LUMO transition (96\%). The optical energy gap is deduced to be $2.50 \mathrm{eV}$ reproducing the experimental one $\left(E_{g}^{o p t}=2.71 \mathrm{eV}\right)$ 
These obtained results confirm our choice and validate the obtained structure model of the modified OMPA (OMFA).

From the fully optimized chemical structure, frontier orbitals such as HOMO and LUMO are computed with 0.02 isovalue and presented in Figure 8. Also, HOMO and LUMO energy levels are computed. The chemical insertion of the dimethyl-amine on the focused site induces a change in the frontier orbitals distribution HOMO/LUMO (Figure 8). For 5-MPA optimized structure, HOMO and LUMO are localized on different sites on the chemical structure. Under the insertion of the dimethyl-amine group, the HOMO and LUMO distributions change. The HOMO localizes essentially on the dimethyl-amine group and in the grafted corresponding phenyl ring (See Figure 8), while the LUMO localizes on the other part of the molecule. On the molecule containing the donor-acceptor system, HOMO electron distributions are localized on the donor fragment, while LUMO ones are localized on acceptor fragments [32-33]. These trends suggest that the insertion of dimethyl units localizes a donor fragment near the modified phenyl ring, and the acceptor one on the other side of the molecule. The change of the local distribution induces an increase of $\mathrm{E}_{\mathrm{HOMO}}$ and a decrease of $\mathrm{E}_{\mathrm{LUMO}}$, and the energy gap $\mathrm{E}_{\mathrm{H}-\mathrm{L}}=\mathrm{E}_{\mathrm{HOMO}}-\mathrm{E}_{\mathrm{LUMO}}$ decreases from 3.14 to $2.37 \mathrm{eV}$ (see Table 2). A focused study shows that a change in the electronic properties has a direct impact on the photo-physical properties [34]. To further showing the charge distribution on the optimized chemical structure of the OMFA oligomer, the molecular electrostatic potential (MEP) of the optimized OMFA is presented in Figure 9. The obtained surface visualizes the charged regions of the studied molecule [35]. Areas with blue color (high electrostatic potential) indicate the absence of electrons while areas with red colors (low electrostatic potential) indicate an abundance of electrons [36]. It is seen that the dimethyl group presents blue color confirming the donating character of the added group, while the $\mathrm{C} \equiv \mathrm{N}$ group presents intense red color confirming the accepting character of this site. These trends are confirming by NBO 
calculation on the OMFA optimized chemical structure. The donor group presents a positive NBO atomic charge, while the acceptor one presents a negative value [36]. NBO analysis shows that the dimethyl-amino added group presents positive NBO atomic charge (0.162), which confirm the addition of a donating moiety on the molecule, while $\mathrm{C} \equiv \mathrm{N}$ group presents a negative NBO atomic charge $(-0.133)$ confirming that $\mathrm{C} \equiv \mathrm{N}$ group is an acceptor site on the molecule.

\section{V-Conclusion}

Using the Knoevenagel condensation reaction we have modified the backbone of our electrosynthesized (OMPA). Experimental and theoretical investigations show that the insertion of the dimethyl-amino group changes their electronic and photophysical properties as a result of an intramolecular charge transfer that occurred between thedonor dimethylamino and the acceptor cyano groups. The induced charge transfer leads to a decrease of the electronic and optical bandgaps. Therefore, enhancing the charge transfer in new organic oligomers should induce lower optical band gaps. Finally, we showed that the post-synthetic chemical modification of our oligophenylene is a versatile molecular engineering tool enabling the design of new materials with modulated functionalities and photophysical properties.

\section{Acknowledgments}

This work has been supported by the Tunisian-French cooperative action CMCU/07G1309. The authors are grateful to Dr. F. Massuyeau for their help in experimental measurements at IMN Nantes. France. The authors acknowledge Bordeaux University's High-Performance Computing Center(http://theo.ism.u-bordeaux1.fr/overview.php) for supporting theoretical calculations done in this work 


\section{References}

[1]. AlSalhi MS, Alam J, Dass LA, Raja M.. International Journal of Molecular Sciences. (2011).https://doi:10.3390/ijms12032036

[2]. Grimsdale AC, Leok Chan K, Martin RE, Jokisz PG, Holmes AB. Chemical Reviews. (2009).https://doi/10.1021/cr000013v.

[3]. Chemek M, Khlaifia D, Massuyeau F, Duvail JL, Faulques E, Wéry J, et al.Synthetic Metals. (2014). http://dx.doi.org/10.1016/j.synthmet.2014.09.004

[4]. Chemek M, Wéry J, Bouachrine M, Paris M, Lefrant S, Alimi K. Synthetic Metals. (2010).https://doi:10.1016/j.synthmet.2010.09.001

[5]. Massuyeau F, Wéry J, Duvail J-L, Lefrant S, Yaya A, Ewels C, et al. Beilstein Journal of Nanotechnology. (2015).https://doi:10.3762/bjnano.6.115

[6]. Wang Q, Dong X, He M, Li M, Tian H, Liu J, et al.. Polymer. (2018). https://doi 10.1016/j.polymer.2018.02.035

[7]. Jaymand M, Hatamzadeh M, Omidi Y.. Progress in Polymer Science. (2015). http://dx.doi.org/doi:10.1016/j.progpolymsci.2014.11.004

[8]. Ryu H, Subramanian LR, Hanack M.Tetrahedron journal. (2006).https://doi:10.1016/j.tet.2006.04.051

[9]. Massuyeau F, Faulques E, Lefrant S, Majdoub M, Ghedira M, Alimi K, et al. Journal of Luminescence. (2011).https://doi:10.1016/j.jlumin.2011.02.010

[10]. Mestiri T, Ghomrasni S, Khlaifia D, Alimi K. Physica B: Condensed Matter. (2018). https:// 10.1016/j.physb.2018.05.009

[11]. Ghomrasni S, Aribi I, Chemek M, Said AH, Alimi K. Optical Materials. (2018). https://doi.org/10.1016/j.optmat.2018.02.035 
[12]. Mestiri T, Chemek M, Rouabeh J, Alimi K. Computational Condensed Matter. (2015). http://dx.doi.org/10.1016/j.cocom.2015.07.001

[13]. Amor SB, Said AH, Chemek M, Ayachi S, Massuyeau F, Wéry J, et al. Journal of Molecular Structure. (2013). http://dx.doi.org/10.1016/j.molstruc.2012.03.050

[14]. Taouali W, Casida M, Chemek M, Haj Said A, Alimi K. Journal of Molecular Modeling ( 2017).https://DOI 10.1007/s00894-017-3227-x

[15]. Becke AD. Physical Review A.;38(6,:3098(1988).

[16]. Frisch, M. J.; Trucks, G. W.; Schlegel, H. B.; Scuseria, G. E.; Robb, M. A.; Cheeseman, J. R.; Scalmani, G.; Barone, V.; Petersson, G. A.; Nakatsuji, H.; Li, X.; Caricato, M.; Marenich, A. V.; Bloino, J.; Janesko, B. G.; Gomperts, R.; Mennucci, B.; Hratchian, H. P.; Ortiz, J. V.; Izmaylov, A. F.; Sonnenberg, J. L.; Williams-Young, D.; Ding, F.; Lipparini, F.; Egidi, F.; Goings, J.; Peng, B.; Petrone, A.; Henderson, T.; Ranasinghe, D.; Zakrzewski, V. G.; Gao, J.; Rega, N.; Zheng, G.; Liang, W.; Hada, M.; Ehara, M.; Toyota, K.; Fukuda, R.; Hasegawa, J.; Ishida, M.; Nakajima, T.; Honda, Y.; Kitao, O.; Nakai, H.; Vreven, T.; Throssell, K.; Montgomery, J. A., Jr.; Peralta, J. E.; Ogliaro, F.; Bearpark, M. J.; Heyd, J. J.; Brothers, E. N.; Kudin, K. N.; Staroverov, V. N.; Keith, T. A.; Kobayashi, R.; Normand, J.; Raghavachari, K.; Rendell, A. P.; Burant, J. C.; Iyengar, S. S.; Tomasi, J.; Cossi, M.; Millam, J. M.; Klene, M.; Adamo, C.; Cammi, R.; Ochterski, J. W.; Martin, R. L.; Morokuma, K.; Farkas, O.; Foresman, J. B.; Fox, D. J. Gaussian, Inc., Wallingford CT, 2016..

[17]. Pesant S, Boulanger P, Côté M, Ernzerhof M. Chemical Physics Letters. (2008).https://doi:10.1016/j.cplett.2007.11.023

[18]. Bourass M, Touimi Benjelloun A, Benzakour M, McHarfi M, Jhilal F, Serein-Spirau F, et al. Journal of Saudi Chemical Society. (2017). http://dx.doi.org/10.1016/j.jscs.2017.01.001. 
[19]D. Khlaifia, F. Massuyeau, Christopher P. Ewels, J. Luc Duvail, E. Faulques, K. Alim, J. Energy Technology \&Environmental Science (2017), https://doi.org/10.1002/slct.201701481

[20] S Bao Li, Yu-Ai Duan, Yun Geng, Hong-Ze Gao, Yong-Qing Qiu, and Zhong-Min Su, RSC Advances. (2013), DOI: 10.1039/C5RA00785B.

[21]. R. Dennington TK, J. Millam,. GaussView, Version 5. , Semichem Inc, Shawnee Mission KS 2009.

[22]Janietz, S, Bradley, D.D.C. Grell, M, Gieberler, C, Inbasekaran, M, Appl. Phys. Lett. (1998); https://doi.org/10.1063/1.122479.

[23] Bredas, J.L.; Silbey, R.; Boudreaux, D.S.; Chance, R.R. J. Am. Chem. Soc. (1983).https://doi.org/10.1021/ja00360a004.

[24]. N. Bouzayen, H. Sadki, M. Mbarek, M. Bouachrine, M.N. Bennani, J.Wéry, K. Alimi, , Polymer Testing (2018), doi: 10.1016/j.polymertesting.2017.12.023

[25]. Camila Gouveia Barbosa DCB, Laura Oliveira Péres, Guy Louarn, Henrique de Santana.J Mater Sci-Mater Electron. (2016). https://DOI 10.1007/s10854-016-5107-z

[26]. Massuyeau F, Duvail JL, Athalin H, Lorcy JM, Lefrant S, Wéry J, et al. Nanotechnology. (2009).https://doi:10.1088/0957-4484/20/15/155701

[27]. Massuyeau F, Faulques E, Athalin H, Lefrant S, Duvail JL, Wéry J, et al. Journal of Chemical Physics. (2009).https://doi:10.1088/0957-4484/20/15/155701

[28] Mbarek M, Massuyeau F, Duvail JL, Wery J, Faulques E, Alimi K. APPL. POLYM. SCI. (2013).https://doi.org/10.1002/app.39496.

[29] M. Govindarajana, K. Ganasanb, S. Periandyc, S. Mohan. Spectrochimica Acta Part A, (2010)https://doi.org/10.1016/j.saa.2010.02.029.

[30]W. Taouali, Mark E. Casida, Ala Aldin M.H.M. Darghouth, K. Alim. Computational Materials Sciencehttps://doi.org/10.1016/j.commatsci.2018.03.038.

- [31] N .O'Boyle, A.Tenderholt ,K. Langner,cclib,J Comput Chem 29 (2008):839845.DOI: $10.1002 /$ jcc. 20823 
[32] Vikramaditya T, Saisudhakar M, Sumithra K. RSC Advances.;6(43):37203-11 (2016).

[33]Kacimi, R., Bourass, M., Toupance, T. et al. Res Chem Intermed (2020). https://doi.org/10.1007/s11164-020-04150-7.

[34] A. K. Narsaria, j. poater, C.F. Guerra, A.W. EHlers, T.A.Hamlin, K.Lammerstma, M.Bickelhaupt, Chem.Eur. J , ( 2020),https://doi.org/10.1002/chem.201905355

[35] Bheema Lingam C, Tewari SP. Computational and Theoretical Chemistry. (2013). http://dx.doi.org/10.1016/j.comptc.2013.07.046.

[36] Mohamed Bourass , Aziz El Alamy, Mohammed Bouachrine.Compte rendus Chimie (2019).https://doi.org/10.1016/j.crci.2019.05.008. 